\title{
Childhood circumstances shape multimorbidity and functional limitation in the old age in England: a life course pathway model
}

\author{
Leo Singer \\ Department of Sociology, Social Policy and Criminology, University of Liverpool, UK \\ Email: I.singer@liv.ac.uk
}

\begin{abstract}
The study presents a pathway model of the risk of multimorbidity and functional limitation from childhood to old age. Childhood circumstances, measured as parents' social class, adverse experiences and child's health, influenced multimorbidity and functional limitation at old age indirectly via material, psychosocial and behavioural pathways. These pathways acted as magnifiers of early inequalities: they enhanced the unequal impacts of the preexisting differences between individuals in socio-economic position, psychological connections and health. The pathway effects measured at age 50-64 years were larger than the total effects of childhood social class, adverse experiences and child's health. Thus preretirement appears to be an important period for the health of ageing adults in England. However, in people suffering from complex multimorbidity the total effect of the adverse experiences of abuse and family dysfunction in childhood surpassed the effect of adult psychosocial circumstances. This suggests an early-life sensitive period for this outcome.

The strength of the paper is that childhood circumstances were approached from a broader angle than the usual focus on either the material conditions or extreme experiences of children. The framework is based on a complex mediation analysis with both parallel and serial mediators where the SEM framework with latent factors is an excellent tool to handle multiple regression relationships and measurement error.
\end{abstract}




\section{Introduction}

Rates of multimorbidity - the co-occurrence of multiple diseases within a person - are increasing in the United Kingdom (Kingston et al. 2018) and globally (Garin et al., 2015). More than a quarter of primary care patients older than 18 years in England have multimorbidity (Cassell et al., 2018). As a result of ageing, multimorbidity tends to combine with a decline in physical functioning (Ryan et al. 2015, Jindai et al. 2016). This reduces quality of life (Bayliss et al., 2012) and leads to more primary care consultations, prescriptions and hospitalisations than in people who have no or a single chronic disease (Cassell et al., 2018).

The prevalence of multimorbidity in people older than 65 years in England is projected to increase from 54\% in 2015 to $68 \%$ in 2035 (Kingston et al., 2018). An additional problem is the persisting inequality in the prevalence of multimorbidity in advanced countries (Tetzlaff et al. 2018; Mondor et al. 2018). People with poorer socio-economic background (Taylor, 2010; Agborsangaya 2012, Schaefer et al. 2012), low education (Johnson-Lawrence, Zajacova \& Sneed 2017; Pathirana \& Jackson 2018), women (Agur et al. 2016), people who smoke, drink alcohol and the physically inactive (Dhalwani et al., 2017) are at higher risk of having multimorbidity in older age.

In order to prevent the growth of prevalence and reduce health inequalities in multimorbidity, we need to better understand what triggers these risks for some and not for others and how they develop over individual lives. In this paper multimorbidity will be considered in conjunction with functional limitations (restrictions in performing fundamental physical and mental actions used in daily life), in order to examine if and to what extent their development differs over the life span. The role of childhood circumstances and extraindividual, social determinants in the long-term development of multimorbidity is another important aspect that has been under-explored (Vetrano et al., 2018). The number of studies that have observed longitudinal trends in multimorbidity and their relationship with extraindividual factors is scarce (Schäfer et al., 2012; Jackson et al., 2015; Pavela and Latham 2015; Dhalwani et al., 2017). Furthermore, these studies did not develop explicit models of the relationships between the proximate and distal factors affecting multimorbidity. This makes the risk of omitted variables more likely. Some relevant factors may have remained "under the radar", while the role of those observed could have been 
inflated or attenuated depending on the failure to control for confounders and the inclusion of mediating factors (Frohlich, Corin and Potvin 2001). This paper builds on existing knowledge by setting out the following research questions:

- What are the effects of childhood circumstances (social class, self-rated health and adverse childhood experiences) on individual differences in old age multimorbidity and functional limitation?

- What is the role of material, psycho-social and behavioural pathways in mediating effects of childhood circumstances on individual differences in old age multimorbidity and functional limitation?

In order to achieve these goals, the study develops a theoretical framework for life course pathways to multimorbidity and functional limitation. It will be empirically tested using data from the English Longitudinal Study of Ageing 2002-2018, including data on the participants' childhood circumstances collected in 2006-2007.

\section{Lifecourse models of health}

Chronic disease and multimorbidity are characterized by a time lag between exposure to negative experiences and diagnosis or manifestation of a chronic disease and later development of other diseases. More specifically, it is the gradual accumulation of mundane experiences, wearing down the body systems rather than rare exceptional events that is characteristic for the period leading to the onset of multimorbidity (Hertzman and Boyce 2010). The onset is socially patterned. For example, socially deprived areas of Scotland acquired multimorbidity 10-15 years earlier than people from affluent areas (Barnett et al. 2012). These features make inequalities in multimorbidity an appropriate subject for life course studies.

Life course analyses explore simultaneously the biological and social contexts and development of individual health and disease (Bartley, Blane, and Davey Smith, 2005). The common premise behind all life course approaches is that the antecedent circumstances in individual life influence the health states and their rate of change across an individual's life 
course. Therefore they explicitly require temporal ordering of exposures and their mutual relationships (Kuh et al., 2003). A variety of theoretical life course models have been formalized (BenShlomo and Kuh 2002). The critical period model assumes that an exposure only has an effect within a circumscribed time window, an observation elaborated earlier by Kuh and Wadsworth (1993). The concept of a sensitive period assumes exposures can act across multiple time windows but some are more sensitive to a specific exposure (BenShlomo and Kuh, 2002).

The accumulation of risk model postulates that factors increasing disease risk or protection from disease accumulate over a life time (Ben-Shlomo and Kuh 2002). For instance, a child from a poor family is more likely to fail at school, leave school at an early age, take up unskilled work that is hazardous and badly paid and, when retired, spend the rest of their life in financial insecurity. Early life advantage or disadvantage sets individuals on diverging pathways or chains of risk, as one exposure leads to another. The process is not deterministic but has been expressed as a probabilistic cascade, capturing how risks build up over time (Ferraro, Schafer and Wilkinson 2016).

Rather than mutually exclusive, both models are combined in research practice (Ben-Shlomo, Cooper and Kuh 2016). Critical (sensitive) period, accumulation and pathways are increasingly treated as mutually entangled trends. For instance, Hallqvist et al. (2004) compared three hypotheses: critical period, accumulation and the role of social mobility in their study of trajectories leading to myocardial infarction. The study found strong interdependence between the critical period, accumulation and social mobility patterns. Despite their interdependencies, it is important to distinguish between critical/sensitive period models and accumulation of risk models because they can inform the timing of possible preventive interventions to reduce health inequalities (Green and Popham, 2017).

\subsection{Socio-economic inequalities}

The Black Report (Black, 1980) put forward four possible explanations for socioeconomic inequalities in health: artefact (no relationship between social class and health), selection (health determines social class position), materialist (multi-faceted social class affects health) and cultural/behavioural (socially patterned risky behaviours affect health). The arrival of life 
course theory allowed to redefine these hypotheses into temporal pathways to be integrated into a coherent framework (Macintyre, 1997; Moor, Spallek and Richter, 2016).

Material pathways link lower social class position to health and mortality through the role of occupational status, income and financial wealth across the life course. Material inequality can affect health in two ways, either by the lack of resources of individuals and/or by the under-investment in services and community infrastructure (Kaplan et al., 1996; Lynch 2000) which may interact. Studies identified a range of determinants, such as working conditions (Benach, Muntaner, Solar et al., 2013), housing conditions (Krieger \& Higgins, 2002), neighbourhood deprivation (Barnett et al., 2012) and environmental pollution (Briggs, 2003). Lack of education is a major determinant through which inequality is passed between generations (Bartley 2017) as it reflects parental social class.

The psychosocial pathway comprises a variety of psychosocial resources, such as leisure, social activities and networks, from the level of the family or household out to wider community and society (Bartley, 2017). These pathways benefit health by providing social support, social influence and attachment, and access to resources and goods (Berkman and Glass, 2000). The perception of control over individual life is another determinant with effects on later health (Whitehead et al., 2016). One pathway from the lack of subjective control acts through a passive response and induced depression, an alternative route is through chronic stress leading to higher risk of cardiovascular disease and lower endocrine and immune function (Bosma, 2006). Research has also reported a relationship between multimorbidity and social support. The risk of multimorbidity was reduced for people living as a couple, in a family, who had a large social network and a sense of control over their lives (Marengoni et al., 2011).

Behavioural pathways (or health behaviours) define ways of consumption and leisure activities that affect health and are, to some extent, modifiable by individual decision-making (Bartley, Blane, and Smith Davey, 2005). Examples of health behaviours include physical activity, smoking, substance use, diet, risky sexual activities, health care seeking and adherence to prescribed medication (Short and Mollborn, 2015). Individuals with a higher number of risk factors are more likely to develop multiple health issues than those who engage in only one type of risky behaviour (Fortin et al. 2014, Dhalwani et al. 2017; 
Katikireddi, 2017). Several theories exist to explain behavioural inequalities. Bourdieu (1984) notes that members of the same class do not consciously choose to act in a risky way. Instead, they reproduce practices, formed within their social locations, which instil them with a corresponding world view and values.

\subsection{Adverse experiences}

Childhoods differ by more than just their socio-economic positions. Adverse childhood experiences (ACEs) include direct harm to children (physical, sexual, verbal abuse) and indirect experiences such as domestic violence, parental separation, substance absuse, mental illness and crime (Hughes et al. 2017). ACEs have been recognized as important determinants of adult health (Felitti, et al., 1998) for adult mental health, respiratory disease, cardio-vascular diseases, cancer, diabetes and risky health behaviours including self-harm (Felitti et al., 1998; Taylor et al. 2015).

The ways in which early adversity contributes to the risk of multimorbidity and functional limitation remains unclear. There is some evidence for the behavioural pathway where individuals with the history of ACEs adopt hazardous lifestyles (Sinnott et al., 2015). Other studies proposed that adversity in childhood creates a vulnerability to increased chronic stress later in life (Raposa et al., 2014) which translates into higher risks of mental and physical health problems (Font and Maguire-Jack, 2016). Therefore early adversity should be considered simultaneously with childhood social class in any life course model of multimorbidity. Distinguishing between the causal chains of social class and those of adverse experiences will help better understand the explanatory mechanisms behind development of adult multimorbidity.

\subsection{Childhood health}

Childhood health is another determinant that can influence later health development of individuals (Haas 2006; Haas and Oi, 2018; Pavela and Latham 2015). Early studies of this relationship used birthweight, child's height and weight as proxies for health or nutrition and showed an inverse relationship between the scores in childhood and later health outcomes (Bartley, Blane, and Smith Davey, 2005). The British Birth cohorts directly examined health development from early years to young and middle age. For example, participants with 
chronic illnesses in childhood were at a higher risk of chronic disease, psycho-social problems and social isolation at age 23 years (Power, 1992). In the U.S., self-reported conditions in childhood were directly associated with cancer, lung disease, cardiovascular conditions, and arthritis/rheumatism in a nationally representative sample of Americans aged 55 to 65 years (Blackwell, Hayward and Crimmins, 2001). The associations were explained by direct biological effects (the critical period) but social pathways were also found to be relevant. Using a U.S. longitudinal study of the period 1968-1996, Haas (2006) developed a mediation model showing that socio-economic deprivation increased risk of poor birth outcomes and childhood illness. Children with worse health later completed education at an earlier age, progressed to lower occupation, leading to lower income and household wealth. The social pathway was associated with worse adult health (Haas, 2006).

3. Life course model of multimorbidity and functional limitation for ageing people in England

Figure 1. represents a framework that postulates pathways to multimorbidity and functional limitation from childhood to the old age. The expectation is that the paths will follow the accumulation of risk model with mediation through independent material, psychosocial and behavioural indirect effects (pathways). The paper adopts a theoretically informed "life stage" approach (Stone, Netuveli and Blane, 2014). It is assumed that a series of social exposures during life will contribute to the total effect on multimorbidity in a cumulative rather than a simple additive effect, i.e. some periods in life have greater importance than others. For this reason, four life stages were chosen where literature has documented specific effects on individual health process. Some of them (childhood, adolescence) can be related to the concept of sensitive period from lifecourse epidemiology (Ben-Shlomo and Kuh, 2002; Stone, Netuveli and Blane, 2014).

The study extends the idea of biological sensitivity to the social terrain by including the cohort aged between 50 and 64 years. In Britain, this is the period in life when individual and household wealth is at its peak and surpasses the role of income (Crawford, Innes and O'Dea, 2016). A detailed analysis of the pathways of accumulation for this age cohort revealed that 
the accumulation is wider than economic, involving psychological and cultural mechanisms (McGovern and Nazroo, 2015). Individual differences in smoking, alcohol consumption, physical activity and BMI at age 59 years predicted higher probability of developing multimorbidity than at younger or older ages (Katikireddi et al., 2017). This adds to the relevance of the pre-retirement life stage for the model, as the focus is on pathways to interindividual differences in old age health.

In order to capture a diversity of experiences that might differ between children, three domains of childhood circumstances will be used: social class, adverse childhood experiences and self-rated health. Their mutual inter-relationships are acknowledged by allowing them to correlate in the model (Hoffman, Kröger and Geyer, 2019). In line with the accumulation of risk theory and the findings summarized in Sections 2.1 to 2.4, the differences in the social class of children are expected to set them on diverging material, psychosocial and behavioural pathways. Children in higher socio-economic positions will increase their likelihood of improving their material and psychosocial circumstances as well as healthrelated behaviours in pre-retirement. These differences will in turn increase their likelihood of lower multimorbidity and functional limitation. Similarly, those who avoided adverse experiences in childhood are expected to be more likely to score better in the measures of adult social class, psychosocial support and health behaviours, which will translate to a lower degree of multimorbidity and functional limitation. The analyses were adjusted for multimorbidity at pre-retirement stage, in order to find out if this variable would mediate some part of the total indirect effect of childhood circumstances (see Figure 1). 


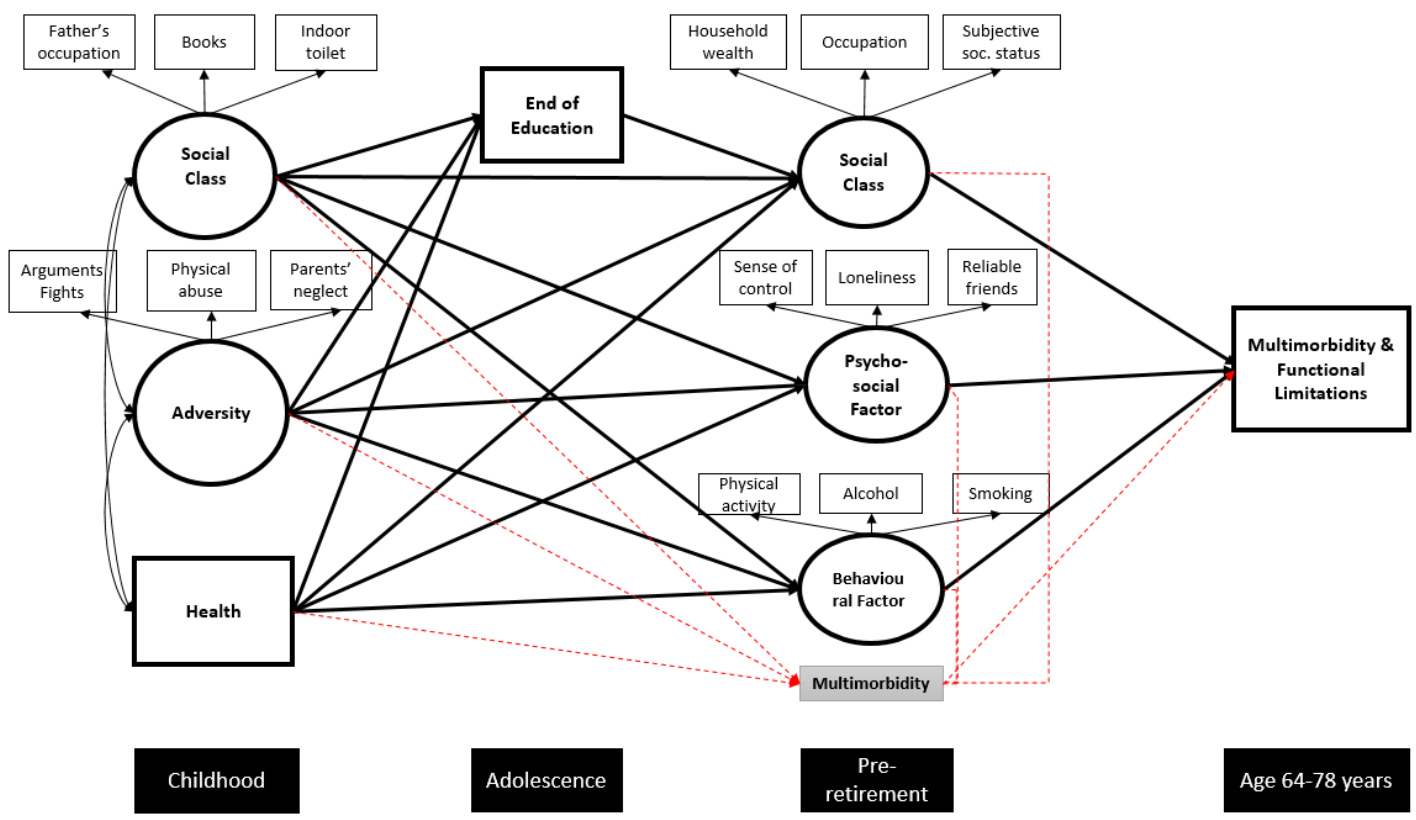

Figure 1. Theoretical framework for lifecourse pathways to multimorbidity and functional limitation. The circles indicate latent variables whilst squares indicate measured variables. The paths to and from pre-retirement multimorbidity are highlighted in dashed red lines.

Several more assumptions in our model of lifecourse multimorbidity include: (a) Moving from left to right assumes passage of time, (b) vertically aligned variables are contemporaneous and (c) relations among contemporaneous variables are correlational. The correlation reflects that the causal order is unknown. (d) directional relations express the passage of time. (e) there are no additional unmeasured confounders in the model (f) measurement error is minimal. These conditions determine the hypothetical path that can exist between two variables in our model (MacKinnon, Fairchild and Fritz, 2007).

\section{Data}

English Longitudinal Study of Ageing (ELSA) is a representative study using a panel of individuals aged 50 years and older in England. ELSA is focused on understanding the physical, psychological, social and economic aspects of ageing. The first wave of ELSA was carried out in 2002 and over 12,000 core sample members and their partners were interviewed during 
this wave. Participants are interviewed every two years and a nurses visit is carried out at every other wave. Life History interviews recorded at wave 3 provide a wide range of data on participants' childhood and later transitions in their lives. By using the unique individual identifiers, data from the Life History interviews were merged with the panel data spanning the period between waves 1 and 8 .

The original number of Life History participants was 7,855 and all were interviewed at wave 3 of the survey. Only those who took part in both waves 1 and 8 were selected, in order to achieve the maximum time lag between the hypothesized mediators and their effects on the outcome. The participants aged 50-64 years (n) at wave 1 were selected and 157 cases were excluded from analysis due to missing values on all variables. The resulting sample size is 3,088 individuals. The complex longitudinal structure of ELSA data was taken into account. By using three types of weights, standard errors and a chi-square test of model fit were computed taking into account stratification, non-independence of observations due to cluster sampling, and the unequal probability of selection.

Table 1. Variables selected for the analysis

\begin{tabular}{lccc}
\hline \multicolumn{1}{c}{ Variable } & Category & Number & Frequency \\
\cline { 2 - 4 } & & & \\
Wave 1 & & & \\
Sex & & & \\
Male & 1 & 1391 & 45.0 \\
Female & 2 & 1697 & 55.0 \\
Occupation & & & \\
High & 1 & 1178 & 39 \\
Intermediate & 2 & 709 & 23.5 \\
Low & 3 & 1130 & 37.5 \\
Household wealth & & & \\
Top & 1 & 835 & 27.6 \\
Medium & 2 & 1858 & 61.4 \\
Low & 3 & 333 & 11 \\
Subj. social status & & & \\
Top & 1 & 591 & 19.4 \\
Medium & 2 & 2215 & 72.8 \\
Low & 3 & 235 & 7.7
\end{tabular}


Sense of control

$\begin{array}{lrrr}\text { Maximum } & 1 & 1245 & 40.8 \\ \text { Some } & 2 & 1691 & 55.4 \\ \text { Low } & 3 & 118 & 3.9 \\ \text { Loneliness } & & & \\ \text { No } & 1 & 2804 & 91.1 \\ \text { Yes } & 2 & 275 & 8.9\end{array}$

Physical activity

$\begin{array}{lrrr}\text { Vigorous } & 1 & 1108 & 35.9 \\ \text { Moderate } & 2 & 1515 & 49.1 \\ \text { Mild } & 3 & 305 & 9.9 \\ \text { No } & 4 & 158 & 5.1 \\ \text { Alcohol consumption } & & & \\ \text { Don't drink } & 1 & 212 & 6.9 \\ \quad \text { Monthly or less } & 2 & 806 & 26.1 \\ \text { Weekly } & 3 & 1145 & 37.1 \\ \text { Daily } & 4 & 925 & 30 \\ \text { Smoking } & & & \\ \text { Never } & 1 & 1171 & 37.9 \\ \text { Ex-smoker } & 2 & 1317 & 42.6 \\ \text { Current smoker } & 3 & 600 & 19.4\end{array}$

Recall at wave 3

Main carers job

$\begin{array}{lrrr}\text { Higher } & 1 & 819 & 26.7 \\ \text { Intermediate } & 2 & 1187 & 38.7 \\ \text { Lower or poor } & 3 & 986 & 32.1 \\ \text { Other } & 4 & 79 & 2.6\end{array}$

Number of books

$\begin{array}{lrrr}\text { Many } & 1 & 548 & 18.5 \\ \text { ISome } & 2 & 1710 & 57.6 \\ \text { Few or none } & 3 & 710 & 23.9 \\ \text { In-door toilet } & & & \\ \text { Yes } & 1 & 2046 & 68.5 \\ \text { No } & 2 & 941 & 31.5\end{array}$

Physical abuse

No

$\begin{array}{lll}1 & 2575 & 96.2\end{array}$

Yes

2103

Parents' neglect

No

12482

92.9

Yes

2190

7.1

Arguments \& Fights

No

$\begin{array}{lll}1 & 2071 & 78.4\end{array}$ 
Child's health

Excellent
Very good
Good
Fair
Poor

$1 \quad 1133$

36.9

21009

32.9

$3 \quad 578$

18.8

$4 \quad 258$

8.4

Educational completion

Age 17 years or older

5

89

2.9

Age 14-16 years

$\begin{array}{lll}1 & 1074 & 34.8\end{array}$

$2 \quad 2013 \quad 65.2$

Wave 8

Basic multimorbidity

0 conditions

1359

16.4

1

$2 \quad 591$

27

2

$3 \quad 531$

24.3

3

4

$>5$ conditions

$4 \quad 379$

17.3

$5 \quad 165 \quad 7.6$

Complex multimorbidity

\begin{tabular}{lllr}
0 ICD chapters & 1 & 360 & 16.5 \\
1 & 2 & 654 & 29.9 \\
2 & 3 & 611 & 28 \\
3 & 4 & 377 & 17.3 \\
$>4$ ICD chapters & 5 & 183 & 8.4 \\
MFLs & & & \\
0 FLs & 1 & 605 & 27.7 \\
1 & 2 & 424 & 19.4 \\
2 & 3 & 278 & 12.7 \\
3 & 4 & 170 & 7.8 \\
4 & 5 & 125 & 5.7 \\
5 to 9 & 6 & 341 & 15.6 \\
10 or more & 7 & 242 & 11.1 \\
& & & \\
\hline
\end{tabular}

\subsection{Measures}

Data on childhood and the age of educational completion originate from selfreported interviews collected in ELSA at wave 3 (2006-07). The variables Adversity, Social Class (in childhood and pre-retirement), Psychosocial Factor and the Behavioural Factor were measured as latent factors. Latent constructs represent processes, which are not directly 
measurable and are only identifiable through chosen indicators. Their advantage and construction is described in Section 5.

\section{Social Class in childhood}

The concept of social class is more appropriate for our aims than the concept of socioeconomic status, which typically reflects direct indicators such as income, educational attainment and occupational classification. This reduces class position to any of single economic issues and complicates the explanation of the underlying mechanisms between social positions and health (Galobardes et al., 2006; Nazroo, 2017). Social class reflects both objective aspects of social stratification as well as its subjective dimension, i.e. cultural differences between people and their selfidentification in the social hierarchy (Kraus, Piff and Keltner 2011).

In the absence of data on parental income and education in ELSA Life History interviews, Social Class was measured by three indicators. The number of books at home exemplifies inter-generational reproduction of social stratification and class identity (Krieger, 2011). The measure was found to independently affect quality of life at later life in Australia (Kendig et al., 2016) suggesting it is a useful measure within our framework. The presence of an indoor toilet at home articulated the aspect of material circumstances of households for children born between 1938 and 1952 in England. The third dimension of social class is represented by the father's or main carer's occupational status, a useful measure of health inequality with origins in the UK (Bartley, 2017).

\section{Adversity}

There is a limited evidence base on the relationship between ACEs and lower income (Font and Maguire-Jack, 2016; Nurius, Fleming and Brindle, 2019), educational attainment (Raposa et al., 2014), divorce or separation (Font and Maguire-Jack, 2016), risky health behaviours, lack of social support (Nurius, Fleming and Brindle, 2019) and multimorbidity (Sinnott et al., 2015). Physical, emotional or sexual abuse had both direct and indirect effects on negative health outcomes in adulthood while experiences of neglect were related only indirectly (Font and Maguire-Jack, 2016). 
The latent variable Adversity was constructed from three binary indicators. The variable Arguments \& Fights was based on the survey question asking whether parents argued or fought very often when the respondent was younger than 16 years of age. The variable Physical Abuse reflects the question whether the respondent was physically abused by their parents when under the age of 16 . The third indicator Parents' Neglect measured whether parents drunk excessively, took drugs or had mental health problems when the respondent was younger than 16 years of age. The three variables were chosen to reflect aspects of both direct and indirect harm (Hughes et al. 2017).

\section{Health}

Self-rated health in childhood, inquired by the question whether the respondent thought their health in childhood was excellent, is coded in five categories: excellent, very good, good, fair or poor.

\section{End of Education}

The effect of education on adult health increases with increasing years of education. Additional time spent in education contributes to lower mortality and risks of chronic conditions (Cutler and Lleras-Muney, 2006). We categorized the variable in two categories, those who left education before the age of 16 and those who stayed in education after 17 years of age.

\section{Social Class in pre-retirement}

An individual's social class before and after retirement in England may have the largest effect through the material resources accumulated since childhood (Nazroo, 2017). These resources are related to previous income, employment and occupational status and combined they affect how individuals perceive their life achievements and social status (Nazroo, 2017). In our study social class in the pre-retirement period will be constructed from three indicators. The net household wealth is the sum of savings, investments, physical wealth and housing wealth after financial debt and mortgage debt were subtracted). It is 
based on 22 distinct components of wealth and debt (Marmot et al., 2016) and divided in three categories (top, medium, low). The second measure is last occupation, re-categorized from the standard NS-SEC classification to three categories (managerial/professional, intermediate, semi/routine). The subjective aspect of the social class will reflected in the measure of the subjective social status (high, medium, low).

\section{Psychosocial Factor}

Psychosocial factors were found to be associated to childhood socio-economic status, health and adversity as well as to later multimorbidity (Pavela \& Latham 2015, Sinnott et al. 2015, Ferraro, Schafer \& Wilkinson 2016). The latent variable Psychosocial Factor was constructed from three indicators, sense of control, loneliness and reliable friends. The variable Sense of control was measured by the question whether the respondent felt that what happened to them was out of their control. Four options were coded to three categories (never, not often/sometimes, often). Having sense of control over life was found a protective factor for the risk of multimorbidity (Marengoni et al. 2011, Melis et al. 2014). The second variable Loneliness (whether respondent felt lonely last week) was binary. Loneliness was associated with multimorbidity in England but the direction of influence remained unclear (Stickley and Koyanagi, 2018). The third variable Reliable Friends had three categories (very/some, a little/not at all, no friends). Supportive friendships as part of social support networks belong to protective factors for multimorbidity (Marengoni et al. 2011).

\section{Behavioural Factor}

Physical activity, tobacco smoking, alcohol consumption, diet and BMI were found to independently predict the risk of multimorbidity in Quebec (Fortin et al. 2014), England (Dhalwani et al. 2016, 2017) and Scotland (Katikireddi 2017). Our latent Behavioural Factor was constructed with three indicators: Physical Activity (vigorous, moderate, mild, none), Alcohol (never, monthly or less, weekly, daily) and Smoking (never, ex-smoker, current smoker). 


\section{Basic multimorbidity}

We follow the most common definition of multimorbidity as "the co-occurrence of two or more diseases within a person" (Van den Akker et al., 1998). This variable was created by summing up the number of morbidities reported by the ELSA participant, separately for each wave of measurement. The minimum number is zero and maximum 5 or more morbidities (Table 2).

\section{Complex multimorbidity}

Complex multimorbidity was defined as "the co-occurrence of three or more chronic conditions affecting three or more different body systems within one person without an index chronic condition" (Harrison et al., 2014, p. 8). We chose it as an alternative measure of multimorbidity as it reflects disease accumulation across disparate body systems. Compared to basic multimorbidity, complex multimorbidity leads to more complex care (Piette and Kerr, 2006) with higher health care utilization. We constructed this measure by selecting only individuals with three or more body systems affected by at least one disease per system. Body systems were classified according to the Chapters of the International Classification of Diseases 10th Revision (ICD-10) (Table 2). We grouped the variable to range between zero chapters and maximum of four or more.

\section{Multiple functional limitations}

The measure of multiple functional limitations was constructed by combining the variables for mobility, Activities of Daily Living (ADL) and on health symptoms (Table 2). ADL refers to the abilities necessary for basic functioning and for living in a community (Chatterji, Byles \& Cutler et al., 2015). The total number of functional limitations per individual was summed up. 
Table 2. Health data used to measure basic multimorbidity, complex multimorbidity and multiple functional limitations

\begin{tabular}{|c|c|c|c|c|}
\hline & Morbidities & Body systems & & Functional limitations \\
\hline 1 & High blood pressure & 1. Eye disorders & & General mobility \\
\hline 2 & Angina & 1.1. Glaucoma & 1 & Walking 100 yards \\
\hline 3 & $\begin{array}{l}\text { Congested heart } \\
\text { failure }\end{array}$ & 1.2. Macular degeneration & 2 & Sitting for $2 \mathrm{hrs}$ \\
\hline 4 & Heart murmur & 1.4. Cataracts & 3 & Getting up from chair \\
\hline 5 & $\begin{array}{l}\text { Abnormal heart } \\
\text { rhythm }\end{array}$ & 2. Circulatory disorders & 4 & Climbing several flights of stairs \\
\hline 6 & Heart attack & 2.1. High blood pressure & 5 & Climbing one flight of stairs \\
\hline 7 & Diabetes & 2.2. Angina & 6 & Stooping, kneeling or crouching \\
\hline 8 & Stroke & 2.3. Heart attack & 7 & Reaching arms above shoulders \\
\hline 9 & Lung disease & 2.4. Congestive heart failure & 8 & Pulling or pushing a chair \\
\hline 10 & Asthma & 2.5. Heart murmur & 9 & Lifting/carrying weights over 10 pounds \\
\hline 11 & Arthritis & 2.6. Abnormal heart rhythm & 10 & Picking up a $5 p$ coin \\
\hline 12 & Osteoporosis & 2.7. Stroke & & Activities of daily living \\
\hline 13 & Cancer & $\begin{array}{l}\text { 3. Endocrine, nutritional and } \\
\text { metabolic }\end{array}$ & 11 & $\begin{array}{l}\text { Dressing, including putting on shoes and } \\
\text { socks }\end{array}$ \\
\hline 14 & Parkinson's disease & 3.1 Diabetic eye disease & 12 & Walking across a room \\
\hline 15 & Dementia & 3.2. Diabetes & 13 & Bathing or showering \\
\hline 16 & Alzheimer's disease & $\begin{array}{l}\text { 4. Musculoskeletal and connective } \\
\text { system }\end{array}$ & 14 & Eating, such as cutting up your food \\
\hline 17 & Hallucinations & 4.1. Osteoporosis & 15 & Getting in or out of bed \\
\hline 18 & Anxiety & 4.2. Arthritis & 16 & $\begin{array}{l}\text { Using the toilet, including getting up or } \\
\text { down }\end{array}$ \\
\hline 19 & Depression & 5. Respiratory & 17 & $\begin{array}{l}\text { Using a map to figure out how to get } \\
\text { around }\end{array}$ \\
\hline 20 & Emotional problems & 5.1. Lung disease & 18 & Preparing a hot meal \\
\hline 21 & Mood swings & 5.2. Asthma & 19 & Shopping for groceries \\
\hline 22 & Glaucoma & 6. Neoplasms & 20 & Making telephone calls \\
\hline 23 & Diabetic eye disease & 6.1. Cancers & 21 & Taking medications \\
\hline 24 & $\begin{array}{l}\text { Macular } \\
\text { degeneration }\end{array}$ & 7. Nervous disorders & 22 & Doing work around the house or garden \\
\hline \multirow[t]{8}{*}{25} & Cataracts & 7.1. Parkinson's disease & 23 & $\begin{array}{l}\text { Managing money (paying bills, track of } \\
\text { expenses) }\end{array}$ \\
\hline & & 7.2. Alzheimer's disease & & Symptoms \\
\hline & & 7.3. Hallucinations & 24 & Difficulty walking 0.25 mile \\
\hline & & 8. Mental and behavioural & 25 & Pain in general \\
\hline & & 8.1. Anxiety & 26 & Problems with eyesight \\
\hline & & 8.2. Depression & 27 & Problems with hearing \\
\hline & & 8.3. Emotional problems & 28 & Balance on level surface \\
\hline & & 8.4. Mood swings & 29 & Dizzy walking on level surface \\
\hline
\end{tabular}

\section{Methods and analyses}

Using Structural Equation Modelling (SEM), the conceptual framework of lifecourse multimorbidity and functional limitation was integrated with the latent factors and other variables (Figure 1). SEM is an extension and combination of multivariate regression analysis, 
path analysis and factor analysis. SEM is commonly used to test hypotheses about simultaneous relationships among variables as well as path effects across time, which makes it appropriate for the needs of our study (Geiser 2013; Schumacker \& Lomax 2016). Another advantage of SEM is its use of latent factors (constructs) that allows to take measurement error into account for both independent and dependent variables. Parameter estimation, especially the regression coefficients for dependent variables, and association between variables are less biased (Warren 2009; Schumacker \& Lomax 2016).

In the first step, bivariate analysis of the associations between variables chosen from the literature review was conducted. Weakly correlated variables were eliminated and those making theoretical sense were further tested in a confirmatory factor analysis (Appendix, Table A2). It was assessed whether the potential explanatory variables shared sufficient variance so that they could be explained by a shared, directly unobservable commonality, a latent factor_(Appendix, Table A2). The paths between measures of childhood circumstances, mediating latent factors (adult Social Class, the Psychosocial Factor and the Behavioural Factor), the confounder (adult multimorbidity) and the outcomes (basic/complex multimorbidity and functional limitation) were then specified.

Stata version 13 was used for data cleaning and to prepare the panel format. The model was estimated with the Weighted Least Square Means and Variance adjusted estimator (WLSMV) in Mplus 7.4. WLSMV has been shown superior to the alternative Maximum Likelihood estimator, as its standard errors are more accurate when data are non-normally distributed and the sample size is large ( $\mathrm{Li}, 2015)$. As a normal distribution of the path effects could not be assumed, their statistical significance was inferred by the bootrapping method rather than the t-test (Taylor, MacKinnon \& Tein 2008). The bias-corrected bootstrap confidence intervals were calculated for standard errors of the path effects by repeated resampling 10 000 times from the raw data with replacement. 


\section{Results}

Table A4 in the Appendix presents the results from three SEMs for our theoretical framework (Figures 2-3), including the assessment of the overall model fit. This section presents the results in their relationship to the two research questions. The study found evidence of indirect effects of the three domains of childhood circumstances on the three health outcomes. The indirect effects were mediated via material, psychosocial and behavioural pathways and via multimorbidity in pre-retirement.

The total indirect (pathway) effect of the social class was 0.255 (Cls: 0.080 to 0.408 ) for basic multimorbidity, 0.265 (Cls: 0.125 to 0.265 ) for complex multimorbidity and 0.320 ( Cls: 0.229 to 0.708 ) for multiple functional limitations. This means that $26 \%$ of the variation in basic multimorbidity, $27 \%$ of the variation in complex multimorbidity and over $32 \%$ in functional limitation can be explained by changes in the pathways. The pathways of the childhood social class varied depending on the outcome. Basic and complex multimorbidity were influenced via all three pathways - material, psychosocial and behavioural - but multiple functional limitations only via the material and behavioural pathways. The paths in Figures 2-3 can be interpreted in the following way. Individuals with lower social class in childhood are more likely to have lower social class as adults which predicts a higher risk of having one of the three health outcomes in old age. For instance, two participants who differed by one unit in their reported childhood social class are estimated to differ, due to their difference on adult social class, by $9 \%$ in the risk of basic multimorbidity, by $8 \%$ in complex multimorbidity and by $6.8 \%$ in the risk of multiple functional limitation at old age. The effect was significant with 95\% BC bootstrap confidence intervals 0.034 to 0.169 in the first model, 0.031 to 0.161 in the second model and 0.005 to 0.312 for functional limitations (Appendix, Table A4). Some of the effect of social class was mediated via the role of education. A shorter school attendance predicted worse material circumstances and more unhealthy behaviours later in life, increasing the risk of multimorbidities and functional limitation (Figures 2-3). 


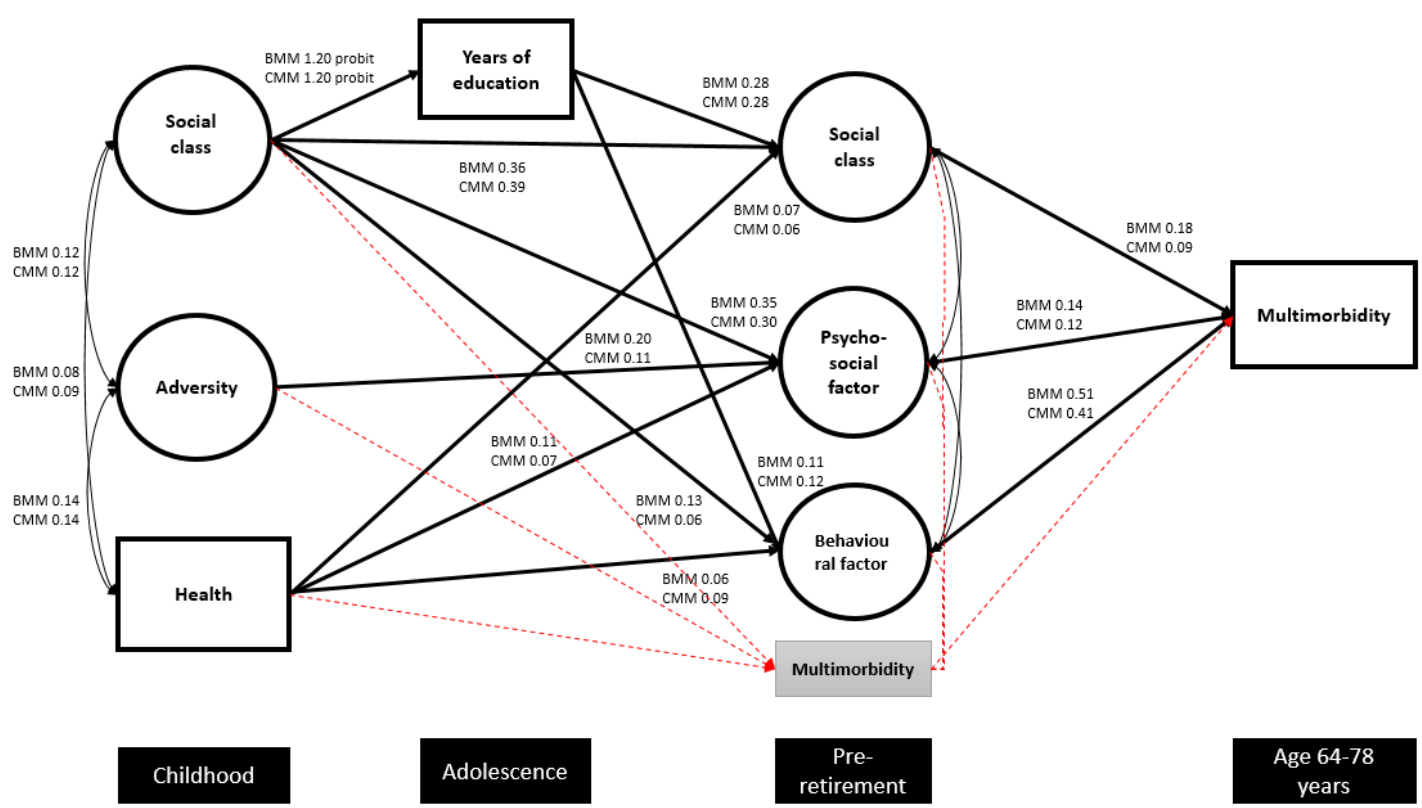

Figure 2. Lifecourse pathways of basic and complex (BMM/CMM) multimorbidity. For the sake of clarity, the correlation values for the pre-retirement mediators and the path coeficients for the pre-retirement $\mathrm{MM}$ are only listed in the Appendix, Table A4.

Adversity in childhood influenced three health outcomes through the psychosocial pathway. The pathway effect of the adverse experiences was 0.239 (Cls: 0.084 to 0.461 ) for basic multimorbidity, 0.169 (Cls: 0.045 to 0.331 ) for complex multimorbidity and 0.245 (Cls: 0.016 to 0.363 ) for multiple functional limitations. This means that $24 \%$ of the variation in basic multimorbidity, $17 \%$ of the variation in complex multimorbidity and almost a quarter of the variation in functional limitation can be explained by changes in the psychosocial pathway from childhood adversity. Due to the Psychosocial Factor, two participants who differed by one unit in their reported ACEs are estimated to differ by $6.6 \%$ in the risk of basic multimorbidity, by $5.7 \%$ in the risk of complex multimorbidity and by $11.3 \%$ in functional limitations. The $95 \%$ BC bootstrap confidence intervals 0.020 to $0.158,0.020$ to 0.115 and 0.029 to 0.742 indicate that we can be $95 \%$ confident that the effects exclude the null effect (Appendix, Table A4). Outside the psychosocial pathway, early adversity exerted some influence via multimorbidity in pre-retirement (Figures 2 and 3).

Childhood health influenced multimorbidities in old age via all three pathways, irrespective of the outcome. The sum of the pathway effects of childhood health was 0.161 (Cls: 0.117 to 0.225 ) for basic multimorbidity, 0.132 (Cls: 0.096 to 0.187 ) for complex multimorbidity and 
0.146 (Cls: 0.078 to 0.667 ) for multiple functional limitations. This means that the variation in the pathways from childhood health can explain $16 \%$ of the variation in basic multimorbidity, $13 \%$ of variation in complex multimorbidity and almost $15 \%$ of variation in functional limitation. Childhood health directly influenced adult social class and childhood social class influenced multimorbidity at pre-retirement age (Figure 2). This indicates a crosslagged type of effect (Warren 2009, Hoffman, Kröger and Geyer 2019).

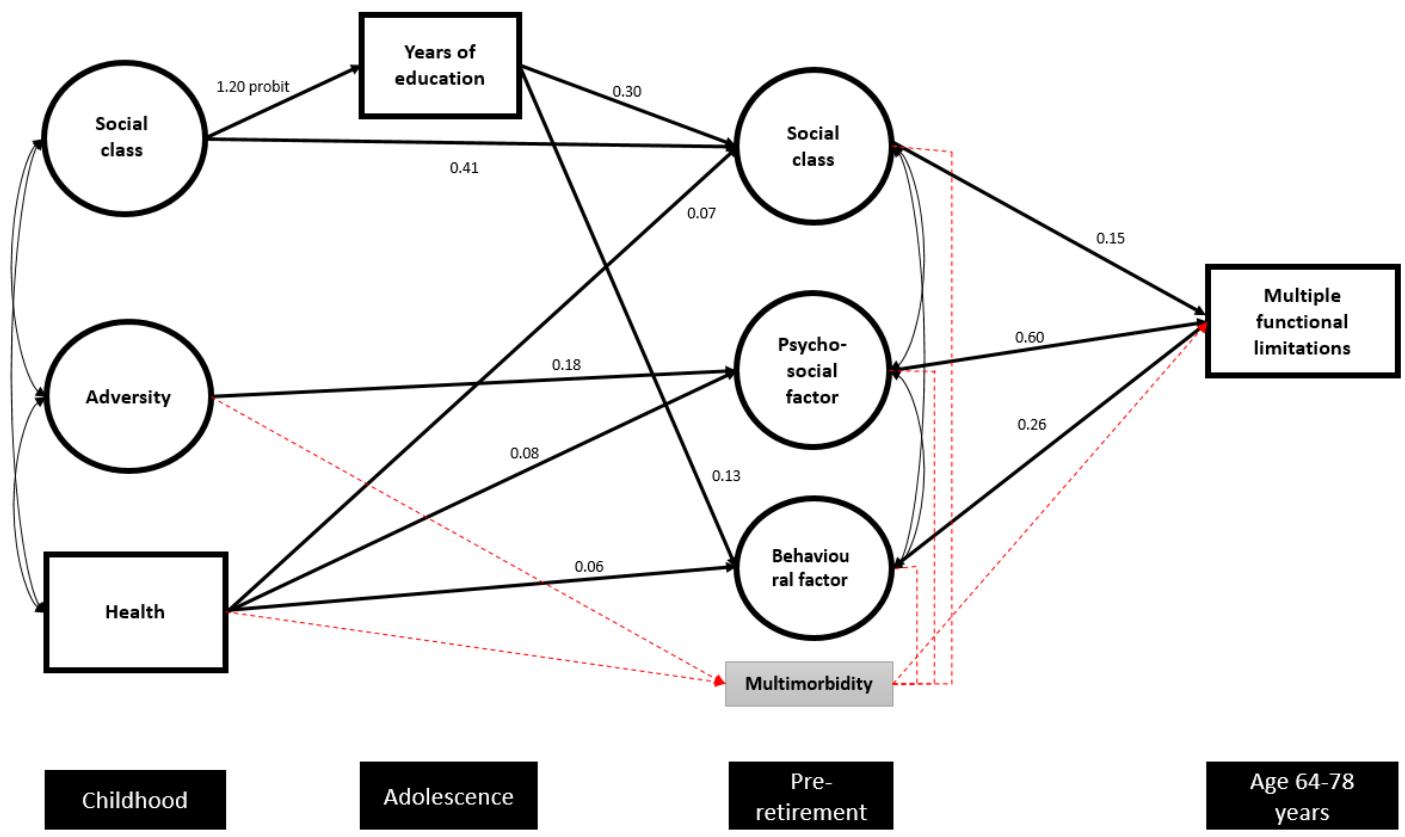

Figure 3. Lifecourse pathways of multiple functional limitations. For the sake of clarity, the correlation values for the pre-retirement mediators and the path coeficients for the pre-retirement MM are only listed in the Appendix, Table A4.

The framework enables to compare and assess the difference in the magnitude of the effects measured at different life stages. The effects of the adult SES, Psychosocial Factor and Behavioural Factor on the old age multimorbidity and functional limitation were larger than the total effects of childhood social class, adverse experiences and child's health. The only exception is complex multimorbidity where childhood adversity had a stronger effect than adult Psychosocial factor (0.239 versus 0.150 ), suggesting a possible early sensitive period. 


\section{Discussion}

\subsection{Key results}

Assessed simultaneously, childhood social class, adverse childhood experiences and childhood health did influence basic/complex multimorbidity and multiple functional limitations in old age. Childhood social class and childhood health affected basic and complex multimorbidity through material, psychosocial and behavioural pathways. Childhood social class influenced functional limitations only via the material pathway. Adversity affected both types of multimorbidity and functional limitation through the psychosocial pathway. Childhood circumstances had no direct effect on basic/complex multimorbidity and functional limitation. The years of completed education were an intervening mechanism influencing material and behavioural pathways from childhood social class to all three outcomes. The effects of the Adult Social Class, Psychosocial Factor and Behavioural Factor on old age multimorbidity and functional limitation were larger than the effects of childhood social class, adverse experiences and child's health. Interestingly, childhood adversity had a stronger effect than the Psychosocial Factor for people with complex multimorbidity.

\subsection{Interpretation}

The study presents a life course model exploring pathways for understanding the risk of multimorbidity and functional limitation from childhood to old age. People in England, who grew up in worse circumstances in childhood than their better-off peers, had a greater risk of multimorbidity and functional limitation when aged 64-78. Childhood circumstances influenced multimorbidity and functional limitation at old age indirectly via the completed years of education in combination with material, psychosocial and behavioural pathways. These pathways acted as magnifiers of early inequalities, in the way that they expanded the unequal impacts of the pre-existing differences between individuals in socio-economic position, psychological connections and health. The pathway effects measured at age 50-64 years were larger than the total effects of childhood social class, adverse experiences and child's health. Preretirement appears to be an important period for adults in England. However, in people suffering from complex multimorbidity the total effect of the adverse 
experiences of abuse and family dysfunction in childhood surpassed the effect of adult psychosocial circumstances, which suggests an early-life sensitive period for this outcome.

The combined effect of childhood social class was pervasive. Those who were born between 1938 and 1952 and grew up in home with fewer financial, material and cultural resources were estimated to be set on a probabilistic trajectory leading through lower accumulated wealth, lower occupational and subjective status (either directly or through the contributing effect of education) to worse health at the age 64-78. Independent from home adversity (presence of abuse, violence or chaos from parents) their family social class predicted the access to psychosocial resources in adulthood such as social networks, reliable friendship or the sense of control over their lives. The cascade of disadvantage in childhood continued to shape their multimorbidity status in old age. Children from these families were more likely to engage in risky health behaviours - less physically active, more smoking and alcohol consumption which in turn translated into higher degrees of multimorbidity. Children born to more affluent conditions were likely to progress in the opposite direction, along all three pathways. Compared to Ferraro, Schaffer and Wilkinson (2016) mediation model of multimorbidity, who found evidence of smoking and lack of personal control as pathways to multimorbidity, we identified a broader range of mediating mechanisms.

As with social class, negative experiences such as physical abuse, domestic violence and substance abuse in a child's home had the potential to set individuals on diverging paths in later life. Adversity predicted a higher burden of multimorbidity via psychosocial attributes such as lack of control in life, social isolation and lack of support from reliable friendships. The results are consistent with Ferraro, Schaffer and Wilkinson (2016) who found mediating effects through smoking, lack of family support and lack of personal control. These associations can be explained with the help of the stress proliferation theory, which states that early adversity increases the likelihood of subsequent stress exposures, undermines selfesteem which makes problematic to build and maintain supporting relationships (Pearlin, 2010). The cascade further increases chances of disease accumulation ( $O^{\prime}$ Rand and HamilLuker, 2005).

Chain of risks between adversity and harmful health behaviours have been well documented (Felitti 2002; Hughes et al. 2017). In this study, physical activity, alcohol consumption and 
smoking were influenced by ACEs only indirectly, via pre-retirement multimorbidity (Figures 2 and 3). A significant pathway between ACEs and adult social class was equally mediated via pre-retirement multimorbidity. Strong clustering of adversity and further diseases might be underestimated in literature as it is less visible than material pathways (Nurius et al., 2017). A recent study reported that the risk of developing chronic diseases for people who experienced multiple ACEs was higher at young age (18-34 years) than at old age (Sonu, Post and Feinglass, 2019). This path model shows that the chain of risks does not stop with adult multimorbidity but affects other determinants of health.

Childhood health directly influenced adult social class and childhood social class influenced health measured as multimorbidity at pre-retirement for both basic and complex multimorbidity (Figure 5.2). This suggests a simultaneous presence of both social causation and health selection in our sample. A similar co-occurrence of both types of effects was reported by Hoffman, Kröger and Geyer (2019) but only for the period between childhood and the age 30-50 years. The relationship between both pathways at later age reflected only social causation. Bi-directional relationships highlight the need to assess both variables jointly rather than choose a single hypothetical direction (causation or selection) a priori.

Life course models of health implicitly rest on the theory that social factors interact with human biology (Diez Roux 2007; Blane et al. 2013) This interaction is part of our lives since the foetal period until death. Therefore an explanation seeking to explain causal mechanisms must consider the role of biology. Material, psychosocial and behavioural pathways would never were able to influence risks of multimorbidity and functional limitation in a patterned stable way, if there were no socio-biological interacting mechanisms. One such mechanism is stress (Pearlin, 2010). In general, poor people experience higher dose of stress due to their living conditions and daily problems with just getting by (Krieger 2011; Bartley, 2017). According to the stress proliferation theory, exposure to one stressor (an event or a process) leads to exposure to other secondary, stressors (Pearlin, 2010). These stresses interact with psychosocial risks such as lack of social support, insecure employment and job strain, all of which are associated with health difficulties. Stress during the life course becomes embodied by changing body's immune and neuroendocrine responses that leads to higher cumulative physiological burden and the onset of disease accumulation (Krieger, 2011). Another biological pathway associated with multimorbidity and functional limitation is chronic 
inflammation (Friedman et al., 2019). Levels of inflammatory proteins rise in a linear fashion with number of chronic conditions in individuals with multimorbidity (Fabbri et al., 2015). A life course study of six European populations identified robust inverse relationship between SES and level of inflammation (Berger et al., 2019). The pathway may be explained by proinflammatory environment in childhood, such as infections, risky health behaviours, and continued pro-inflammatory factors in later life (Berger et al., 2019).

\subsection{Strengths and limitations}

This paper developed and tested a life course model of pathways leading to old age multimorbidity and functional limitation. Childhood circumstances were approached from a broader angle than the usual focus on either the material conditions or extreme experiences of children. The framework integrated multi-causality with accumulation, the two key features essential for explaining development of multimorbidity over time. It was based on a complex mediation analysis with both parallel and serial mediators where the SEM framework with latent factors is an excellent tool to handle multiple regression relationships and measurement error. Bias-corrected bootstrapping is a more powerful approach to statistical inference than the normal theory testing (Hayes, 2013). The bootstrap confidence intervals follow the irregularity of sampling distribution and the inferences are more accurate than when using the normal theory approach.

Compared with the three other life course studies of multimorbidty and functional limitation (Pavela and Latham, 2015; Ferraro, Schaffer and Wilkinson, 2016; Haas and Oi, 2018), this study improved the methodology and study design in several aspects. It developed a model with clear temporal lags between observations. It intervened against the possibility of a spurious effect by adding a variable for multimorbidity measured simultaneously with potential mediators. SEM with latent factors enabled to make stronger statistical inference about the standard errors while the other reviewed studies relied on observed variables only. From a conceptual perspective, this paper considered a range of material, behavioural and psychosocial resources and risks, an approach also taken by Pavela and Latham (2015) and Ferraro, Schafer and Wilkinson (2016). 
As a retrospective study, the information on the circumstances in early life was dependent on participants' subjective recall. This introduces a potential bias but studies have shown that the difference relates to the magnitude of associations, not changes to direction of effects (Niedzwiedz et al., 2012). Reliability of recall in ELSA was tested in comparison with prospective data from the 1958 Birth Cohort by selecting participants of similar age and the same time point (Jivraj et al., 2017). The results were the most similar for parental occupation, but in general, statistical significance and direction of effects were similar but not the magnitude of regression coefficients. A general limitation common to all life course studies is the potential bias from selective survival (Liu, Jones and Glymour, 2010; Niedzwiedz et al., 2012). Childhood experience of poverty and illnesses may lead to premature mortality, thus the cohort aged 64-78 might have been pre-selected into those had a more advantageous early life. This potentially underestimates the disparities between individuals, which are due to the childhood circumstances.

\section{Conclusion}

In conclusion, the study has shown that the conceptualization of lifecourse pathways into material, psychosocial and behavioural, dating back to the Black Report (Black, 1980), is useful and can explain how social exposures shape the risks of health problems into the old age. Unlike the usual focus on pathways of socioeconomic status, it identified three types of pathways across three domains of early life disadvantage simultaneously. Depending on the domain and the health outcome, these pathways explained between 13 percent (the pathways from health to complex multimorbidity) and 32\% (the pathways from social class to functional limitation) of the variation in the outcomes. The remaining variance can be attributed to the effect of multimorbidity in pre-retirement which we took into account and the remaining unexplained factors.

Rather than the individual strength of any particular relationship, it is the range of childhood factors and their relationships with a number of social determinants of health that is the most striking. The findings show that a variety of pathways is operating between early life and adult health and a lifecourse approach to multimorbidity is vital (Kuh and Wadsworth, 1993). 
The study provides a convincing argument for life course models to integrate dimensions of social class, psychosocial adversity and health. The results supported the hypothesis that multi-dimensional childhood circumstances shape later-life multimorbidity through a diversity of social, psycho-social and socio-biological pathways. The approach to childhood circumstances developed in this paper will be beneficial for those researchers who are interested in exploring early life effects on other multi-factorial and cumulative outcomes (processes) than multimorbidity and functional decline, such as disability, frailty or allostatic load.

\section{Acknowledgements}

This paper would not have been possible without the support of $\mathrm{Dr}$ Mark Green and $\mathrm{Dr}$ Francisco Rowe (University of Liverpool), Professor Yoav Ben-Shlomo (University of Bristol) and Dr Karyn Morrissey (University of Exeter).

\section{References}

Agborsangaya, C. B., et al. (2012) 'Multimorbidity prevalence and patterns across socioeconomic determinants: a cross-sectional survey', BMC public health, 12, 201. doi:10.1186/1471-2458-12-201

Agur, K., et al. (2016) 'How does sex influence multimorbidity? Secondary analysis of a large nationally representative dataset', International journal of environmental research and public health, 13(4), 391. doi:10.3390/ijerph13040391

Arpino, B., Gumà, J., and Julià, A. (2018) 'Early-life conditions and health at older ages: The mediating role of educational attainment, family and employment trajectories', PLoS ONE, 13(4):e0195320. https://doi.org/10.1371/journal.

pone.0195320 
Barnett, K. et al. (2012) 'Epidemiology of multimorbidity and implications for health care, research, and medical education: a cross-sectional study', The Lancet, 380(9836), pp. 37-43. DOI:10.1016/S0140- 6736(12)60240-2.

Bartley, M., Blane, D., and Smith Davey, G. (2005). The sociology of health inequalities. Oxford: Blackwell's.

Bartley M., and Blane, D. (2016). Reflections on the legacy of British health inequalities research. In K. Smith, C. Bambra and S. Hill (Eds.), Health Inequalities: critical perspectives. Oxford Scholarship Online doi:10.1093/acprof:oso/9780198703358.003.0002

Bayliss, E. A., et al. (2014) 'Understanding the context of health for persons with multiple chronic conditions: moving from what is the matter to what matters', Annals of family medicine, 12(3), 260-269. doi:10.1370/afm.1643

Blackwell, D., Hayward, M., and Crimmins, E. (2001) 'Does childhood health affect chronic morbidity in later life?', Social Science \& Medicine, 52(8), pp. 1269-1284. https://doi.org/10.1016/S0277-9536(00)00230-6

Benach, J., et al. (2013) 'Employment, work and health inequalities: a global perspective'. DOI: $10.13140 / 2.1 .3521 .1528$.

Ben-Shlomo, Y., and Kuh, D. (2002) 'A life course approach to chronic disease epidemiology: conceptual models, empirical challenges and interdisciplinary perspectives', International Journal of Epidemiology, 31(2), pp. 285-293, https://doi.org/10.1093/ije/31.2.285

Ben-Shlomo, Y., Cooper, R., and Kuh, D. (2016) 'The last two decades of life course epidemiology, and its relevance for research on ageing', International journal of epidemiology, 45(4), pp. 973-988. doi:10.1093/ije/dyw096

Berkman, L.F. and Glass, T. (2000) Social integration, social networks, social support and health. In: Berkman, L.F. and Kawachi, I., Eds., Social Epidemiology, Oxford University Press, New York, 158-162.

Berger, E. et al. (2019) 'Multi-cohort study identifies social determinants of systemic inflammation over the life course', Nature communications, 10(1), doi:10.1038/s41467-01908732-x 
Birnie, K. et al. (2011) 'Childhood socioeconomic position and objectively measured physical capability levels in adulthood: a systematic review and metaanalysis', PloS one, 6(1), e15564. doi:10.1371/journal.pone.0015564

Bollen, K., and Stine, R. (1990) 'Direct and indirect effects: classical and bootstrap estimates of variability', Sociological methodology, 20, pp. 115-140. https://www.jstor.org/stable/pdf/271084.pdf

Bosma, H. (2006). Socio-economic differences in health: are control beliefs fundamental mediators? In: J. Siegrist and M. Marmot (Eds.), Social Inequalities in Health: New Evidence and Policy Implications. Oxford University Press:

Oxford.

Bourdieu, P. (1984). Distinction: a social critique of the judgement of taste. London: Routledge.

Bowen, M. E., and González, H. M. (2010) 'Childhood socioeconomic position and disability in later life: results of the health and retirement study', American journal of public health, 100 Suppl 1(Suppl 1), pp.197-S203. doi:10.2105/AJPH.2009.160986

Briggs, D. (2003) 'Environmental pollution and the global burden of disease', British Medical Bulletin, 68(1), pp. 1-24. https://doi.org/10.1093/bmb/ldg019

Cassel, A. et al. (2018) 'The epidemiology of multimorbidity in primary care: a retrospective cohort study', British Journal of General Practice; 68(669): e245e251. DOI: https://doi.org/10.3399/bjgp18X695465

Cohen, S., et al. (2010) 'Childhood socioeconomic status and adult health', Annals of the New York Academy of Sciences, 1186, pp. 37-55. doi: 10.1111/j.1749$6632.2009 .05334 . x$

Cole, D., and Preacher, K. (2014) 'Manifest variable path analysis: potentially serious and misleading consequences due to uncorrected measurement error',

Psychological $\quad$ 300-315.

http://www.quantpsy.org/pubs/cole_preacher_2014.pdf 
Crawford, R., Innes. D. and O’Dea, C. (2016) 'Household wealth in Great Britain: distribution, composition and changes 2006-12', Fiscal Studies: The Journal of

Applied Public Economics, 37(1), pp. 35-54. https://doi.org/10.1111/j.14755890.2016.12083

Davey Smith, G., Blane, D., and Bartley, M. (1994) 'Explanations for socioeconomic differentials in mortality: Evidence from Britain and elsewhere',

European Joumal Public Health, 4, pp. 131-44.

https://doi.org/10.1093/eurpub/4.2.131

Dhalwani, N. et al. (2017) 'Association between lifestyle factors and the incidence of multimorbidity in an older English population', The Journals of

Gerontology: Series A, 72(4), pp. 528-534.

https://doi.org/10.1093/gerona/glw146

Due, P. et al. (2011) 'Pathways and mechanisms in adolescence contribute to adult health inequalities', Scandinavian Journal of Public Health, 39(Suppl 6), pp. 62-78. https://journals.sagepub.com/doi/pdf/10.1177/1403494810395989

Felitti, V. et al. (1998) 'Relationship of childhood abuse and household dysfunction to many of the leading causes of death in adults: The Adverse Childhood Experiences (ACE) Study', American Journal of Preventive Medicine, 14, pp. 245-258. https://doi.org/10.1016/S07493797(98)00017-8

Ferraro, K. F., Schafer, M. H., \& Wilkinson, L. R. (2016). Childhood Disadvantage and Health Problems in Middle and Later Life: Early Imprints on Physical Health?. American sociological review, $\quad 81(1), 107-133$. doi:10.1177/0003122415619617

Font, S. A., and Maguire-Jack, K. (2016) ‘Pathways from childhood abuse and other adversities to adult health risks: the role of adult socioeconomic conditions', Child abuse \& neglect, 51, pp. 390-399. doi:10.1016/j.chiabu.2015.05.013

Fortin, M., et al. (2014) 'Lifestyle factors and multimorbidity: a cross sectional study', BMC public health, 14(686). doi:10.1186/1471-2458-14-686

Friedman, E. M., Mroczek, D., and Christ, S. (2019) 'Multimorbidity, inflammation, and disability: a longitudinal mediational analysis', Therapeutic Advances in Chronic Disease. https://doi.org/10.1177/2040622318806848 
Frohlich, K., Corin, E., \& Potvin, L. (2001). A theoretical proposal for the relationship between context and disease. Sociology of Health \& Illness, 23(6), 776-797. https://doi.org/10.1111/1467-9566.00275

Galobardes, B. et al. (2006) 'Indicators of socioeconomic position (part 1)', Journal of Epidemiology and Community Health, 60(1), pp. 7-12. PMID:16361448

Garin, N., et al. (2016) 'Global multimorbidity patterns: A cross-sectional, population-based, multi-country study, The journals of gerontology. Series A,

Biological sciences and medical sciences, 71(2), 205-214. doi:10.1093/gerona/glv128

Geiser, C. (2013,) Data Analysis with Mplus. New York: The Guilford Press.

Green, M. J., \& Popham, F. (2017). Life course models: improving interpretation by consideration of total effects. International journal of epidemiology, 46(3), 1057-1062. doi:10.1093/ije/dyw329

Hallquist, J. et al. (2004) 'Can we disentangle life course processes of accumulation, critical period and social mobility? An analysis of disadvantaged socio-economic positions and myocardial infarction in the Stockholm Heart Epidemiology Program', Social Science \& Medicine, 58(8), pp. 1555-62. https://doi.org/10.1016/S0277-9536(03)00344-7

Haas, S. A. (2006) 'Health selection and the process of social stratification: the effect of childhood health on socioeconomic attainment', Journal of Health and

$\begin{array}{llll}\text { Social } & \text { Behavior, } & \text { 47(4), } & \text { 339-354. }\end{array}$

https://doi.org/10.1177/002214650604700403

Haas, S. and Oi, K. (2018) 'The developmental origins of health and disease in international perspective', Social Science \& Medicine, 213, pp. 123-133. https://doi.org/10.1016/j.socscimed.2018.07.047

Hertzman, C. and Boyce, T. (2010) 'How experience gets under the skin to create gradients in developmental health', Annual review of Public Health, 31, pp. 329347. doi: 10.1146/annurev.publhealth.012809.103538. 
Hoffmann, R., Kröger, H., and Geyer, S. (2019) 'Social causation versus health selection in the life course: does their relative importance differ by dimension of SES?', Social Indices Research, 141(3), pp. 1341-1367. https://doi.org/10.1007/s11205-018-1871-x

Hu, L., and Bentler, P. (1999) 'Cutoff criteria for fit indexes in covariance structure analysis: conventional criteria versus new alternatives', Structural Equation Modeling, 6, pp. 1-55. doi:10.1080/10705519909540118

Jackson, C., et al. (2015) 'Body mass index and socioeconomic position are associated with 9year trajectories of multimorbidity: A population-based study', Preventive Medicine, 81, 9298. https://doi.org/10.1016/j.ypmed.2015.08.013.

Jivraj, S.. et al. (2017) 'Testing comparability between retrospective life history data and prospective birth cohort study data', The Journals of Gerontology: Series B, , gbx042, https://doi.org/10.1093/geronb/gbx042

Johnson-Lawrence, V., Zajacova, A., and Sneed, R. (2017) 'Education, race/ethnicity, and multimorbidity among adults aged 30-64 in the National Health Interview Survey', Social Science \& Medicine - Population Health, 3, pp. 366-372. doi:10.1016/j.ssmph.2017.03.007

Kaplan, G. A., et al.. (1996) 'Inequality in income and mortality in the United States: analysis of mortality and potential pathways', BMJ (Clinical research ed.), 312(7037), pp. 999-1003. doi:10.1136/bmj.312.7037.999

Katikireddi, S. V. et al. (2017) 'The contribution of risk factors to socioeconomic inequalities in multimorbidity across the lifecourse: a longitudinal analysis of the Twenty-07 cohort', BMC medicine, 15(1). doi:10.1186/s12916-017-0913-6

Kendig, H. et al. (2016) 'Pathways to well-being in later life: socioeconomic and health determinants across the life course of Australian baby boomers', Journal of population ageing, 9, pp. 49-67. doi:10.1007/s12062-015-9132-0

Kingston, A. et al. (2018) 'Projections of multi-morbidity in the older population in England to 2035: estimates from the Population Ageing and Care Simulation

(PACSim) model', Age and Ageing, 47(3), pp. 374-380, https://doi.org/10.1093/ageing/afx201 
Kraus, M. W., Piff, P. K., and Keltner, D. (2011) 'Social class as culture: the convergence of resources and rank in the social realm', Current Directions in

Psychological Science, 20(4), pp. 246-250.

https://doi.org/10.1177/0963721411414654

Krieger, J., and Higgins, D. L. (2002) 'Housing and health: time again for public health action', American Journal of Public Health, 92(5), pp. 758-768. doi:10.2105/ajph.92.5.758

Kuh, D. et al. (2003) 'Life course epidemiology', Journal of Epidemiology \& Community Health, 57, pp.778-783.

Kuh, D., and Wadsworth, M. (1993) 'Physical health status at 36 years in a British national birth cohort', Social Science and Medicine, 37(7), pp.905-916.

https://doi.org/10.1016/0277-9536(93)90145-T

Licher, S., et al. (2019) 'Lifetime risk and multimorbidity of non-communicable diseases and disease-free life expectancy in the general population: a population-based cohort study', PLoS medicine, 16(2), e1002741. doi:10.1371/journal.pmed.1002741

Liu, S., Jones, R. and Glymour, M. (2010) 'Implications of lifecourse epidemiology for research on determinants of adult disease', Public Health Review, 32(2), pp. 489-511.

Lynch, J. (2000) 'Income inequality and health: expanding the debate', Social Science \& Medicine, 51(7), pp. 1001-1005. https://doi.org/10.1016/S02779536(00)00080-0

MacKinnon, D. P., Fairchild, A., and Fritz, M. S. (2007) 'Mediation analysis',

Annual review of psychology, 58, pp. 593-614. doi:10.1146/annurev.psych.58.110405.085542

Macintyre, S. (1997) 'The Black Report and beyond: what are the issues?', Social Science \& Medicine, 44(6), pp. 723-45. doi: 10.1016/s0277-9536(96)00183-9.

Marengoni, A. et al. (2011) 'Aging with multimorbidity: a systematic review of the literature', Ageing Resesearh Revue, 10, pp. 430-439. doi:

10.1016/j.arr.2011.03.003. 
McGovern, P. and Nazroo, J. (2015) 'Patterns and causes of health inequalities in later life: a Bourdieusian approach', Sociology of Health \& Illness, 37(1), pp.

143-160. https://doi.org/10.1111/1467-9566.12187

McLean, G. et al. (2014) 'The influence of socioeconomic deprivation on multimorbidity at different ages: a cross-sectional study', The British journal of general practice : the journal of the Royal College of General Practitioners', 64(624), e440-e447. doi:10.3399/bjgp14X680545

Mondor, L., et al. (2018) 'Income inequalities in multimorbidity prevalence in Ontario, Canada: a decomposition analysis of linked survey and health administrative data', International journal for equity in health, 17(1), doi:10.1186/s12939-018-0800-6

Muthén, B., and Asparouhov, T. (2015) 'Causal effects in mediation modeling: an introduction with applications to latent variables', Structural Equation

Modeling: $\quad$ A $\quad$ Multidisciplinary Journal, 22(1), pp. $12-23$ doi: $10.1080 / 10705511.2014 .935843$

Nazroo, J. (2017) 'Class and health inequality in later life: patterns, mechanisms and implications for policy', International journal of environmental research and public health, 14(12), 1533. doi:10.3390/ijerph14121533

Nurius, P. S. et al. (2019) 'Life course pathways from Adverse Childhood

Experiences to adult physical health: a Structural Equation Model', Journal of Aging and Health, 31(2), 211-230. https://doi.org/10.1177/0898264317726448

Pavela, G., and Latham, K. (2016) 'Childhood Conditions and Multimorbidity Among Older Adults', The journals of gerontology. Series B, Psychological sciences and social sciences, 71(5), 889-901. doi:10.1093/geronb/gbv028

Pearlin, L. (2010) 'The life course and the stress process: some conceptual comparisons', The journals of gerontology. Series B, Psychological sciences and social sciences, 65B(2), pp. 207215. doi:10.1093/geronb/gbp106

Power, Ch. (1992) 'A review of child health in the 1958 birth cohort: National Child Development Study', Paediatric and Perinatal Epidemiology, 6, pp. 81-110.

https://doi.org/10.1111/j.1365-3016.1992.tb00748.x 
Preacher, K. (2015) 'Advances in mediation analysis: a survey and synthesis of new developments', Annual Review of Psychology, 66, pp. 825-852. https://doi.org/10.1146/annurev-psych-010814-015258.

Raphael, D. (2010) 'The health of Canada's children. Part II: Health mechanisms and pathways', Paediatrics \& child health, 15(2), pp. 71-76. doi:10.1093/pch/15.2.71

Raposa, E. B. et al. (2014) 'Early adversity and health outcomes in young adulthood: the role of ongoing stress', Health psychology: official journal of the Division of Health Psychology, American Psychological Association, 33(5), pp. 410-418. doi:10.1037/a0032752

Robertson, T., et al. (2015) 'The role of material, psychosocial and behavioral factors in mediating the association between socioeconomic position and allostatic load', Brain, behavior, and immunity, 45, pp. 41-49. doi:10.1016/j.bbi.2014.10.005

Ryan, A. et al. (2015) 'Multimorbidity and functional decline in communitydwelling adults: a systematic review', Health and Quality of Life Outcomes, 13(168). DOI 10.1186/s12955-0150355-9

Schaefer, I. (2012) 'Does multimorbidity influence the occurrence rates of chronic conditions? A claims-data based comparison of expected and observed prevalence rates', PLOS One, 7(9). https://doi.org/10.1371/journal.pone.0045390.

Schoon, I., and Melis, G. (2019) 'Intergenerational transmission of family adversity: examining constellations of risk factors', PloS One, 14(4), e0214801. doi:10.1371/journal.pone.0214801

Schumacker, R. and Lomax, R. (2016) A Beginner's Guide to Structural Equation Modelling. New York: Routledge.

Selig, J. and Preacher, K. (2009) 'Mediation models for longitudinal data in developmental research', Research in Human Development, 6(2-3), pp. 144-164.

https://doi.org/10.1080/15427600902911247

Short, S. E., and Mollborn, S. (2015) 'Social determinants and health behaviors: conceptual frames and empirical advances', Current opinion in psychology, 5, 78-84. doi:10.1016/j.copsyc.2015.05.002 
Sinnott, C. et al. (2015) 'Psychosocial complexity in multimorbidity: the legacy of adverse childhood experiences', Family Practice, 32(3), pp. 269-275. https://doi.org/10.1093/fampra/cmv016

Sonu, S., Post, S. and Feinglass, J. (2019) 'Adverse childhood experiences and the onset of chronic disease in young adulthood', Preventive Medicine, 123, pp. 163-

170. https://doi.org/10.1016/j.ypmed.2019.03.032

Stickley, A., \& Koyanagi, A., (2018). Physical multimorbidity and loneliness: a populationbased study. PLoS ONE, 13(1), e0191651. http://doi.org/10.1371/journal.pone.0191651

Stone, J., Netuveli, G., and Blane, D. (2014) 'Life-course occupational social class and health in later life: the importance of frequency and timing of measures', European journal of ageing, 11(3), pp.. 273-284. doi:10.1007/s10433-014-0307-y

Strand, B. H. et al. (2011) 'Lifelong socioeconomic position and physical performance in midlife: results from the British 1946 birth cohort', European journal of epidemiology, 26(6), pp. 475-483. doi:10.1007/s10654-011-9562-9 Taylor A., MacKinnon D. and Tein, Y-E. (2008) 'Tests of the three-path mediated effect', Organizational Research Methods, 11(2), pp. 241269. https://doi.org/10.1177/1094428107300344

Taylor, A. et al. (2010) 'Multimorbidity - not just an older person's issue: results from an Australian biomedical study', BMC Public Health, 10(718)

Taylor, J.. et al. (2016) 'Child maltreatment: pathway to chronic and long-term conditions?', Journal of Public Health, 38(3), pp. 426-431. https://doi.org/10.1093/pubmed/fdv117

Tetzlaff, J. et al. (2018) 'Widening inequalities in multimorbidity? Time trends among the working population between 2005 and 2015 based on German health insurance data', International journal for equity in health, 17(1), 103. doi:10.1186/s12939-018-0815-z

Van den Akker, M., et al. (1998) 'Multimorbidity in general practice: prevalence, incidence and determinants of co-occurring chronic and recurrent diseases', Journal of Clinical Epidemiology, 51(5), 367-370. https://doi.org/10.1016/S0895-4356(97)00306-5 
Van Lenthe, F. et al. (2014) 'Cohort profile: understanding socioeconomic inequalities in health and health behaviours: The GLOBE study', International Journal of Epidemiology, 43(3), pp. 721-730, https://doi.org/10.1093/ije/dyt040

Vetrano, D.. et al.. (2018) 'An international perspective on chronic multimorbidity: approaching the elephant in the room', The Journals of

Gerontology: Series A, 73(10), pp. 1350-1356.

https://doi.org/10.1093/gerona/glx178

Wadsworth M. and Kuh, D. (1997) 'Childhood influences on adult health: a review of recent work from the British 1946 national birth cohort study, the MRC National Survey of Health and Development', Paediatric Perinatal

Epidemiology, 11(1):2-20. PMID: 9018723

White, H. et al. (2013) 'Modeling the cumulative effects of social exposures on health: moving beyond disease-specific models', International Journal of Environmental Research and Public Health, 10(4), pp. 1186-1201. http://doi.org/10.3390/ijerph10041186

Whitehead, M., et al. (2016). How could differences in "control over destiny" lead to socioeconomic inequalities in health? A synthesis of theories and pathways in the living environment. Health \& Place, 39, 51-61. DOI:

10.1016/j.healthplace.2016.02.002. 



\section{Appendix}

Table A.1 Polychoric correlation with variables selected for the analysis

\begin{tabular}{|c|c|c|c|c|c|c|c|c|c|c|c|}
\hline & Arguments \& Fights & $\begin{array}{l}\text { Parents' } \\
\text { neglect }\end{array}$ & $\begin{array}{l}\text { Physical } \\
\text { abuse }\end{array}$ & $\begin{array}{l}\text { No. of } \\
\text { books }\end{array}$ & $\begin{array}{l}\text { Father's/Carer's } \\
\text { occupation }\end{array}$ & $\begin{array}{l}\text { In-door } \\
\text { toilet }\end{array}$ & $\begin{array}{c}\text { Occupational } \\
\text { level }\end{array}$ & $\begin{array}{l}\text { Household } \\
\text { wealth }\end{array}$ & $\begin{array}{l}\text { Subjective } \\
\text { social } \\
\text { status }\end{array}$ & $\begin{array}{l}\text { Sense of } \\
\text { control }\end{array}$ & Loneliness \\
\hline \multicolumn{12}{|l|}{ Arguments \& Fights } \\
\hline Parents' neglect & 0.606 & & & & & & & & & & \\
\hline Physical abuse & 0.571 & 0.480 & & & & & & & & & \\
\hline No. of books & -0.085 & -0.149 & 0.008 & & & & & & & & \\
\hline Father's/Carer's occupation & -0.020 & -0.040 & -0.049 & 0.355 & & & & & & & \\
\hline In-door toilet & -0.053 & 0.024 & -0.046 & -0.329 & -0.241 & & & & & & \\
\hline Occupational level & -0.010 & -0.033 & 0.034 & 0.326 & 0.269 & -0.213 & & & & & \\
\hline Household wealth & -0.026 & -0.051 & -0.093 & 0.294 & 0.274 & -0.214 & 0.464 & & & & \\
\hline Subjective social status & -0.042 & -0.043 & -0.061 & 0.259 & 0.208 & -0.126 & 0.390 & 0.478 & & & \\
\hline Sense of control & -0.125 & -0.085 & -0.151 & -0.008 & -0.031 & 0.038 & 0.052 & 0.133 & 0.216 & & \\
\hline Loneliness & -0.130 & -0.112 & -0.089 & 0.152 & 0.114 & -0.115 & 0.205 & 0.300 & 0.282 & 0.286 & \\
\hline End of education & 0.075 & 0.040 & 0.031 & 0.496 & 0.376 & 0.256 & 0.546 & 0.410 & 0.400 & 0.173 & 0.140 \\
\hline \multicolumn{12}{|l|}{ Baseline Model fit index } \\
\hline Chi-square (df) & $9166.932(55)^{* * *}$ & & & & & & & & & & \\
\hline
\end{tabular}


Table A.2 Measures of latent constructs with significance and model fit

\begin{tabular}{|c|c|c|c|c|}
\hline Observed variable & $\begin{array}{l}\text { Latent construct } \\
\text { (LC) }\end{array}$ & B & SE & R-Square \\
\hline Father's/Carer's occupation & Childhood SC & $0.560 * * *$ & 0.025 & $0.313^{* * *}$ \\
\hline In-door toilet & Childhood SC & $0.319^{* * *}$ & 0.037 & $0.102^{* * *}$ \\
\hline Number of books & Childhood SC & $0.629 * * *$ & 0.027 & $0.395^{* * *}$ \\
\hline Arguments \& Fights & $\begin{array}{l}\text { Adversity } \\
\text { Adversity }\end{array}$ & $0.752^{* * *}$ & 0.043 & $0.566^{* * *}$ \\
\hline Parents' neglect & Adversity & $0.766^{* * *}$ & 0.048 & $0.586^{* * *}$ \\
\hline Physical abuse & Adversity & $0.721^{* * *}$ & 0.044 & $0.520^{* * *}$ \\
\hline Occupational level & Adversity & $0.610^{* * *}$ & 0.022 & $0.372^{* * *}$ \\
\hline Household wealth & & $0.731^{* * *}$ & 0.019 & $0.535^{* * *}$ \\
\hline Subjective social status & & $0.683^{* * *}$ & 0.020 & $0.466^{* * *}$ \\
\hline Loneliness & Psycho-social factor & $0.677^{* * *}$ & 0.050 & $0.458^{* * *}$ \\
\hline Sense of control & Psycho-social factor & $0.360^{* * *}$ & 0.034 & $0.194^{* * *}$ \\
\hline Reliable friends & Psycho-social factor & $0.377^{* * *}$ & 0.040 & $0.142^{* * *}$ \\
\hline Physical activity & Behavioural factor & $0.426 * * *$ & 0.038 & $0.181^{* * *}$ \\
\hline Smoking & Behavioural factor & $0.328^{* * *}$ & 0.032 & $0.107^{* * *}$ \\
\hline \multicolumn{5}{|l|}{ Fit indices } \\
\hline Model Chi-square (df) & $394.913^{* * *}(91)$ & & & \\
\hline RMSEA $(90 \% \mathrm{Cl})$ & $0.033(0.030-0.036)$ & & & \\
\hline CFI & 0.959 & & & \\
\hline TLI & 0.924 & & & \\
\hline
\end{tabular}


Table A.3 Correlation between the latent factors

\begin{tabular}{lrrrrr} 
& \multicolumn{1}{c}{ Childhood SC } & Adversity & Adult SC & PS Factor & BH Factor \\
Childhood SC & & 1 & & & \\
Adversity & $0.165^{* * *}$ & 1 & & & \\
Adult SC & $0.660^{* * *}$ & $0.108^{* * *}$ & 1 & & \\
P-S Factor & $0.280^{* * *}$ & $0.345^{* * *}$ & $0.631^{* * *}$ & 1 & 1 \\
BH Factor & $0.449^{* * *}$ & $0.135^{* * *}$ & $0.806^{* * *}$ & $0.660^{* * *}$ &
\end{tabular}


Table A.4 Pathway effects from childhood circumstances to basic/complex multimorbidity and functional limitation

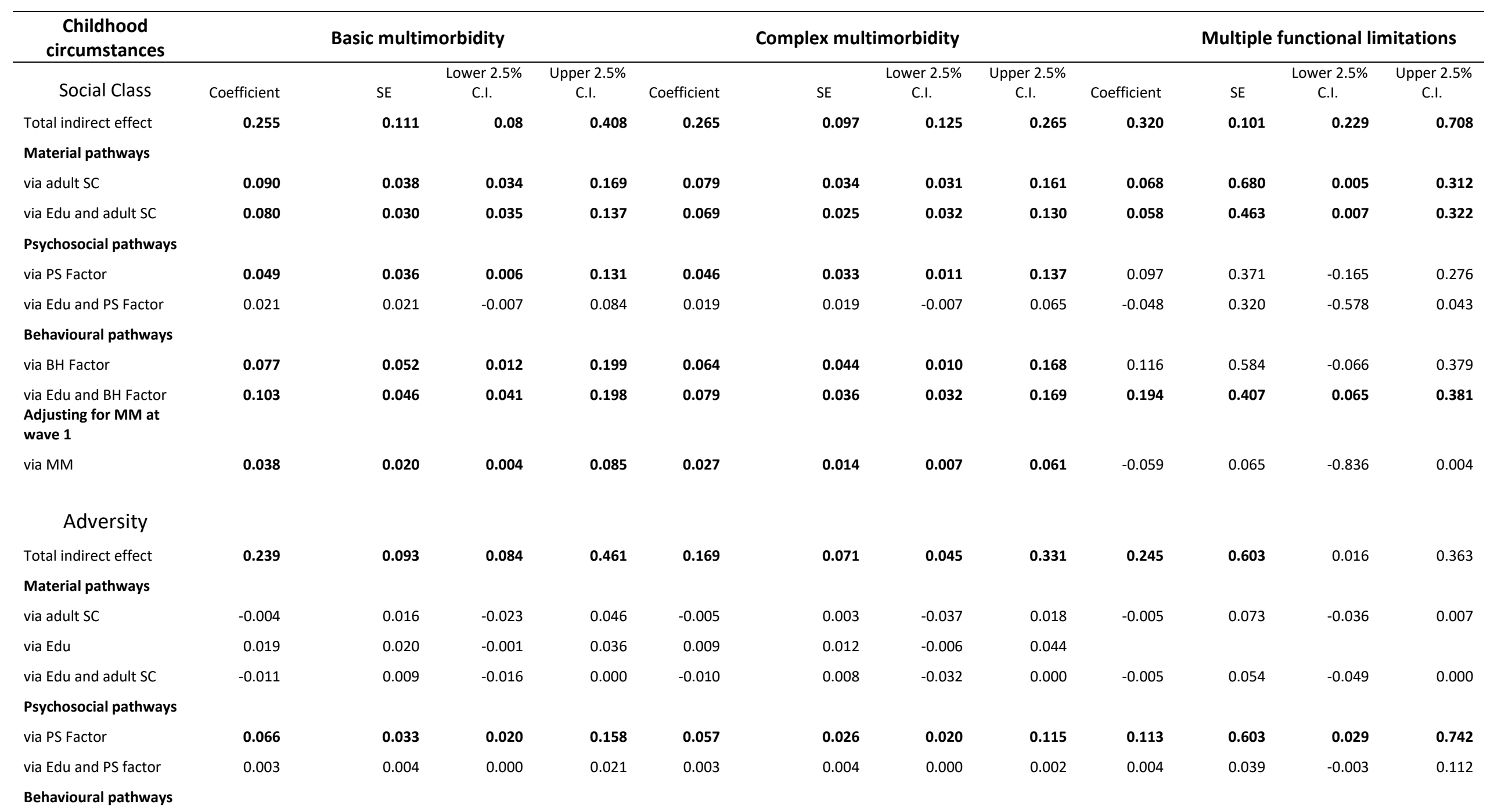




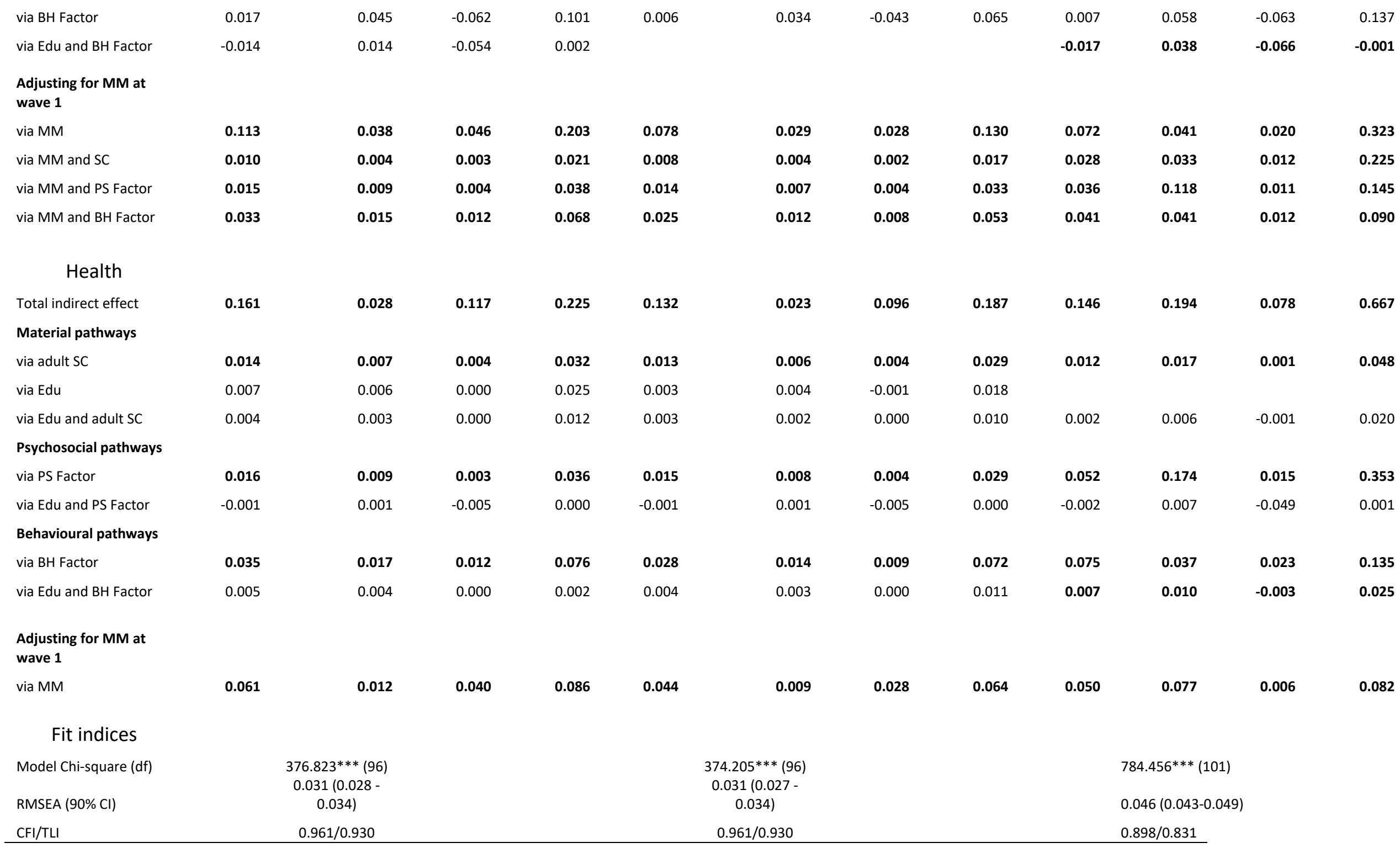


Mediation effects were tested for statistical significance. This involved testing the significance of the paths between each childhood exposure and each adult latent factor and the paths from the mediating factors to the outcomes (MacKinnon, Fairchild and Fritz 2007). We could not assume a normal distribution of the path effects and their statistical significance was inferred by the bootrapping method rather than the t-test (Taylor, MacKinnon \& Tein, 2008). The bias-corrected bootstrap confidence intervals were calculated for standard errors of the path effects.

The chi-square fit index tests whether the sample variance-covariance matrix and the model generated variance-covariance matrix are similar. Statistical significance implies that this difference might be due to the sampling variation while a statistically non-significant chi-square value indicates that the theoretical model significantly reproduces the actual data structure. However, the usefulness of this test has been discussed due to its sensitivity to sample size. With increasing sample size (above 200), the chi-square test tends to show a significant probability value which may lead to an exclusion of a wellspecified model (Schumacker and Lomax 2016). The chi-square value generated by our analysis was statistically significant. Given the mentioned sample size sensitivity and our aims being to assess the role of pathways and not to search for the best fitting parsimonious model, we do not see this as a reason for rejecting our model. In addition, the complementary fit indices RMSEA, CFI and TLI showed acceptable levels of fit. 